\title{
Recuperação de um acervo: uso da Radiação Gama (Cobalto 60) na descontaminação de objetos do acervo do Instituto de Estudos Brasileiros - USP
}

\author{
Paulo Roberto Rela, Fátima Faria Gomes, Lúcia Elena Thomé, Yasko Kodama ${ }^{1}$
}

\section{Resumo}

O Instituto de Estudos Brasileiros (IEB) da Universidade de São Paulo recebeu em caráter provisório parte do acervo do Banco Santos cedido pela Justiça Federal de São Paulo. Este acervo foi lacrado num galpão, pelo Departamento de Polícia Federal, o qual foi inundado pelas águas de chuva, sendo severamente infestado por insetos xilófagos e por microorganismos (fungos). Devido à grande quantidade de material - matrizes de xilogravura, impressos dessas matrizes, manuscritos de literatura de cordel - e urgência da situação, foi necessário buscar um método de tratamento eficiente: que possibilitasse uma desinfestação em grande escala, não trouxesse nenhum risco a integridade do acervo e ao seu manuseio. Após estudos e experiência prévia no processo de irradiação em madeira, decidiu-se submeter prontamente o material à radiação gama. Depois do tratamento o acervo foi recuperado pela equipe de técnicos e estagiários do IEB, sendo, posteriormente, colocado junto às demais coleções do instituto e disponibilizado aos pesquisadores.

\section{Palavras-chave:}

restauração de madeira, radiação gama, restauração de papel

1 Tecnologista Sênior da Comissão Nacional de Energia Nuclear, do Instituto de Pesquisas Energéticas e Nucleares. Doutor em Tecnologia Nuclear pela Universidade de São Paulo; Especialista em conservação e restauro do IEBUSP; Coordenadora do Serviço de Conservação e Restauro do IEB-USP; Tecnologista do Instituto de Pesquisas Energéticas e Nucleares. Mestre pelo IPEN.

Trabalho apresentado na VI Semana de Museus da USP (“A formação de coleções em museus: desafios na democratização das políticas de coleta, aquisição e exibição”), ocorrida de 14 a 18/05/2007; no $1^{\circ}$ Simpósio Latino Americano sobre "Métodos Físicos e Químicos em Arqueologia, Arte e 


\title{
Art Collection preservation: Gama-radiation application for decontaminating objects in the Instituto de Estudos Brasileiros
}

Paulo Roberto Rela, Fátima Faria Gomes, Lúcia Elena Thomé, Yasko Kodama

\begin{abstract}
The Instituto de Estudos Brasileiros (IEB) from the University of São Paulo received the charge from São Paulo's Federal Justice to take care of part of the collection from Banco Santos that was severely attacked by insects and micro-organisms (moulds) when stored in a warehouse that was flooded by intense rainfall. A chemical treatment to eliminate the biodeteriorating agents was tried but it was not effective. As the heap has a large amount of Xylograph wood dye, printings and manuscripts from cordel literature an urgent way to treat was searched and after the study and previous experience on wood irradiation process it was decided to submit promptly the heap to gamma irradiation. After the treatment the peaces were restored by IEB staff and now is being part of IEB collection and available for the scientific research community.
\end{abstract}

\section{Keywords:}

wood restoration, gamma irradiation, paper restoration

Conservação do Patrimônio Cultural”, no Museu de Arte de São Paulo, de 11 a 16/06/2007; e no Workshop "Conservação Preventiva e Planos de Emergência para Proteção do Patrimônio Cultural”, no Museu Abílio Barreto em Belo Horizonte - MG, de 27 a 30/11/2007. 


\section{Introdução}

Em 2005, o Instituto de Estudos Brasileiros da Universidade de São Paulo recebeu, em caráter provisório, parte do acervo que pertenceu ao Banco Santos, cedido pela Justiça Federal de São Paulo. Este acervo é composto por cerca de 1.700 manuscritos de cordel, 3.400 matrizes de xilogravura e em torno de 850 impressões em papel pardo que envolviam muitas dessas matrizes. Antes da vinda para o instituto, o material estava num galpão lacrado pelo Departamento de Polícia Federal. 0 galpão sofreu uma inundação devido a fortes chuvas. Ao permanecer um bom período em um ambiente com temperatura e teor de umidade favoráveis ao crescimento de microorganismos, o acervo foi altamente contaminado por fungos e bactérias - o que se somou ao fato de as matrizes de madeira também apresentarem infestação por insetos xilófagos (cupins e brocas), aumentando ainda mais o processo de deterioração ${ }^{2}$.

Tendo em vista essas condições foi preciso agir prontamente. A opção pelo congelamento, que é uma alternativa a ser utilizada nestes casos, não foi possível: primeiro, devido a problemas de logística ao não se encontrar uma câmara de congelamento disponível com o volume requerido, face ao tamanho do acervo. Segundo, esse método não elimina a causa da deterioração de forma eficaz pois pode levar somente a um estado de dormência dos insetos, levando à necessidade de repetição do processo.

A possibilidade de aplicação de produtos químicos, por exemplo, o óxido de etileno, que é utilizado para esterilização de produtos médicos descartáveis, foi descartada, pois a legislação nacional impede a sua utilização para outros produtos além dos médico-descartáveis, visto que deixa resíduos carcinogênicos. Outros países, como o Canadá e os Estados Unidos, estão reavaliando a possibilidade de sua liberação a partir de garantias de segurança fornecidas pelas indústrias ${ }^{3}$. A reaplicação de agentes fumigantes poderia não atingir a eficiência desejada e, mais grave, aumen-

2 Para uma descrição inicial do processo, ver DETTINO, B. M. A. Tratamento de salvaguarda em situação de emergência: a atuação do IEB em acervo cedido pela Justiça Federal de São Paulo. Revista do Instituto de Estudos Brasileiros, São Paulo, n. 44, p. 275-279, fev. 2007.

3 DAWSON, John E. Solving museum insect problems: chemical control. Technical Bulletin, Canadian Conservation Institute, n. 15, p. 1-26, 2000; DIGNARD, Carole; MASON, Janet. Integrated pest management. In: Preventive conservation in museums. Montreal: Université du Québec; Centre de conservation du Québec, 1995. p. 33-42 
taria a concentração de resíduos acima dos níveis permitidos e certamente problemas toxicológicos para manuseios futuros.

Procuraram-se alternativas para decidir pelo melhor tratamento, que fosse eficiente, rápido e que não causasse qualquer dano aos objetos em si ou riscos para os técnicos que manipulariam diretamente o acervo. Com base em estudos existentes na área ${ }^{4}$, a radiação gama foi sugerida como uma alternativa segura e efetiva para o seu tratamento, uma vez que é largamente utilizada com elevada eficiência na redução da carga microbiana ou eliminação de infestação de pragas em produtos médicos, alimentos, produtos farmacêuticos e produtos agrícolas, sem deixar nenhum resíduo tóxico.

Para o estudo da viabilidade técnica e desenvolvimento do presente trabalho foi feito o contato com o Instituto de Pesquisas Energéticas e Nucleares-IPEN por meio de seu Centro de Tecnologia das Radiações-CTR, já que este desenvolveu no país irradiadores industriais que utilizam gama multipropósito e possui um corpo técnico voltado para aplicação da radiação ionizante em processos industriais e preservação do meio ambiente.

\section{Utilização da irradiação ionizante no tratamento e recuperação do acervo}

Inicialmente as obras foram avaliadas quanto ao nível e tipo de infestação. Constatou-se que estavam severamente atacadas por fungos e por insetos xilófagos e que necessitavam de tratamento no menor prazo possível para não aumentar o risco de uma perda irreversível. Selecionamos algumas ilustrações que apresentam o dano causado pela biodeterioração do acervo (Fig.1).

A seguir foram feitos estudos baseados em levantamentos bibliográficos e na experiência acumulada a respeito da qualificação do produto (acervo) com relação ao processo, ou melhor, se os materiais que fazem parte da composição do produto, como as fibras dos papéis e os pigmentos, poderiam ser tratados por radiação ionizante, e, sendo possível, qual a tolerância à radiação de modo a não alterar as sua propriedades funcionais. Para a desinfestação de insetos em qualquer um de seus estágios de desenvolvimento (ovo, larva, pulpa ou adulto) a quantidade de radiação absorvida pelo produto inferior a $500 \mathrm{~Gy}$ é suficiente para causar a sua letalidade. Um Gray corresponde

4 RIZZO, Márcia et al.. Effects of gamma rays on a restored painting from the XVIIth century. Radiation Physics and Chemistry, n. 63, p. 259-262, 2002. 
à energia de um joule absorvida em um kilograma do produto irradiado. No caso da desinfecção de fungos e bactérias as doses envolvidas são mais elevadas e da ordem de $10 \mathrm{kGy}$.

Para avaliação da viabilidade do tratamento por radiação gama no acervo de modo que não houvesse degradação das propriedades funcionais e aceleração do processo de envelhecimento, havia a necessidade de realizar ensaios microbiológicos para identificação do tipo de fungo presente nas obras e provas de irradiação para a determinação dos valores de doses que levariam a sua letalidade. Estes experimentos deveriam ser conjugados com ensaios que permitissem estudar a variação das propriedades físico-químicas em função das doses de radiação. 0s tempos estimados foram superiores a seis meses de trabalho. Como o estado do acervo não permitia esta demora, decidiu-se, com base na literatura e experiência prévia dos pesquisadores do CTR:

* Parar imediatamente o processo destrutivo das obras, que estava acelerado;

* Restaurar os objetos de grande valor cultural.

$\mathrm{Na}$ definição da dose de radiação para as matrizes de xilogravura levou-se em consideração a contaminação com fungos e foi estabelecida a dose de 10kGy, que normalmente é utilizada como dose de segurança para desinfecção de fungos e bactérias presentes em ingredientes de alimentos (especiarias e ervas desidratadas). Essa dose foi também utilizada em estudos realizados na recuperação de pinturas contaminadas por microorganismos, tendo se mostrado eficaz ${ }^{5}$. Não houve preocupação com a degradação da madeira, uma vez que experimentos realizados anteriormente no CTR revelaram que a degradação, ou melhor, a fragilização ocorre a partir de 50kGy.

Para os impressos e manuscritos em que havia uma grande variação do tipo de papel empregado, optou-se, com base na literatura, por uma dose inferior a $5 \mathrm{kGy}$, que não provoca danos neste tipo de material ${ }^{6}$. Além do mais, diferentemente das matrizes de xilogravura, no papel a contaminação é superficial

5 RIZZO, Márcia et al.. Effects of gamma rays on a restored painting from the XVIIth century. Radiation Physics and Chemistry, n. 63, p. 259-262, 2002.

6 GONZALES, M. E. et al. Gamma radiation for preservation of biologically damaged paper. Radiation physics and chemistry, n. 63, p. 263-265, 2002; MAGAUDA, Giuseppe. The recovery of biodeteriorated books and archive documents through gamma irradiation: some considerations on the results achieved. Journal of Cultural Heritage, n. 5, p. 113-118, 2004; SINCO, Patrick. The use of gamma rays in book conservation. Nuclear News, p. 38-40, April 2000. 
e no caso de ocorrer o recrescimento dos fungos em razão da insuficiência da dose de radiação, este é facilmente percebido por identificação visual.

Na preparação para a irradiação as obras foram catalogadas, higienizadas superficialmente e embaladas em sacos de polietileno selados, de modo a não permitir sua recontaminação pelo meio ambiente. A figura 2 apresenta as etapas de preparação.

Para o tratamento por radiação ionizante utilizou-se o irradiador gama multipropósito do IPEN-CTR, totalmente construído com tecnologia nacional. As obras foram previamente identificadas com selos indicativos do processo, tipo "yes/no" e posicionadas no interior da câmara de irradiação conforme indicação da figura 3. Durante o processo de irradiação foram posicionados dosímetros para garantir que a dose correta fosse absorvida pelos produtos. Na dosimetria ou controle de qualidade do processo foram utilizados dosímetros PMMA tipo Red Perpex 4034 lote de fabricação GD de fabricação Harwell (Inglaterra), com calibração rastreável pelo International Dose Assurance Service (IDAS) da International Atomic Energy Agency (IAEA).

\section{Restauração}

\subsection{Matrizes de xilogravura}

Após o tratamento por radiação gama as obras retornaram ao IEB-USP para serem restauradas por seus profissionais especializados e estagiários, sendo efetivamente catalogadas, acondicionadas com segurança e disponibilizadas para pesquisa na reserva técnica juntamente com os demais acervos do instituto.

As matrizes foram submetidas a um processo de higienização com álcool etílico a $70 \%{ }^{7}$ para a eliminação das colônias de fungos desativadas pela radiação gama. A etapa seguinte foi restaurar as placas fragilizadas tanto pela ação da água durante a enchente, infestação por fungos, quanto pelo ataque dos insetos xilófagos (cupins e brocas).

Muitas dessas matrizes foram gravadas em placas de compensado que, após o período em que estiveram no galpão sob a ação da inundação, apresentavam as camadas descoladas e, algumas, apodrecidas.

7 Conforme orientação sugerida por Maria Beatriz Bacellar Monteiro, pesquisadora do IPT, para a higienização das matrizes. 
Na seqüência do processo de restauração, estas placas foram desmontadas para a remoção de pregos e placas de metal oxidados (enferrujados) e resíduos deixados pelos cupins e brocas. Posteriormente foram coladas com cola à base de PVA neutra e as partes danificadas pelos insetos foram preenchidas com material similar ao suporte: serragem com dois tipos diferentes de granulação, aglutinada com cola de PVA.

A figura 4 apresenta fotos da restauração de xilogravuras.

\subsection{Impressões de xilogravura}

As impressões de xilogravura que envolviam as matrizes estavam bastante deterioradas. A maioria achava-se infestada por colônias de fungos que fragilizaram as fibras do papel além de causarem manchas nos mesmos (Fig. 5).

Devido às situações de armazenagem descritas anteriormente, os papéis também se encontravam bastante fragilizados, com rasgos, manchas, acidez e perdas. Pelo fato de cada impresso envolver sua respectiva matriz, eles apresentavam marcas de dobras e fitas adesivas ainda aderidas.

Os procedimentos de restauro desenvolvidos e aplicados foram os seguintes:

a. Fotografia numerada de todas as impressões, sendo esta numeração a mesma da matriz e da caixa às quais se referia;

b. Remoção mecânica e com calor das fitas adesivas;

c. Remoção química com solvente dos resíduos de cola decorrentes da fita adesiva;

d. Banho em cuba com água deionizada e hidróxido de cálcio para atenuar as manchas e neutralizar a acidez;

e. Planificação em prensa de cada uma das impressões;

f. Preenchimento das partes faltantes com papel japonês tingido em tonalidade próxima ao do impresso ou, em caso de grande perda e fragilização do suporte, velatura de toda a folha.

Ao término de todo o processo de restauração tanto das matrizes como dos impressos, eles foram acondicionados em embalagens adequadas a sua tipologia e conservação. Essas embalagens foram desenvolvidas levando-se em conta que, dentro 
dos preceitos da conservação preventiva, seu material deve ser neutro (pH próximo a 7) e inerte (sem reação ou liberação de gases prejudiciais aos objetos ao longo do tempo) - além de proporcionar estabilidade, segurança e proteção contra poeira e luz.

\section{Conclusão}

Apesar de ainda ser considerado um procedimento polêmico por alguns profissionais da área, no presente trabalho, em decorrência da necessidade de um tratamento emergencial, a utilização da radiação gama mostrou-se rápida e eficiente na eliminação dos agentes biológicos (microorganismos e insetos xilófagos) responsáveis pela deterioração de obras de artes confeccionadas em madeira e papel.

As doses aplicadas aos objetos foram selecionadas, após estudos e pesquisas, para serem eficientes na eliminação dos agentes biodeteriorantes e não provocarem alterações nas propriedades funcionais dos materiais processados.

A radiação gama apresentou-se também como alternativa viável no aspecto técnico e econômico para os tratamentos de eliminação desses agentes em obras de arte, além de permitir o manuseio do acervo com segurança pelos profissionais que entraram em contato direto com o mesmo.

Após os procedimentos de restauração e acondicionamento, este acervo pode ser colocado em reserva técnica juntamente com os demais acervos da instituição e disponibilizado para posterior pesquisa pelo público especializado. 
Figura 1: Xilogravuras e impressos infestados por insetos e contaminadas por fungos.
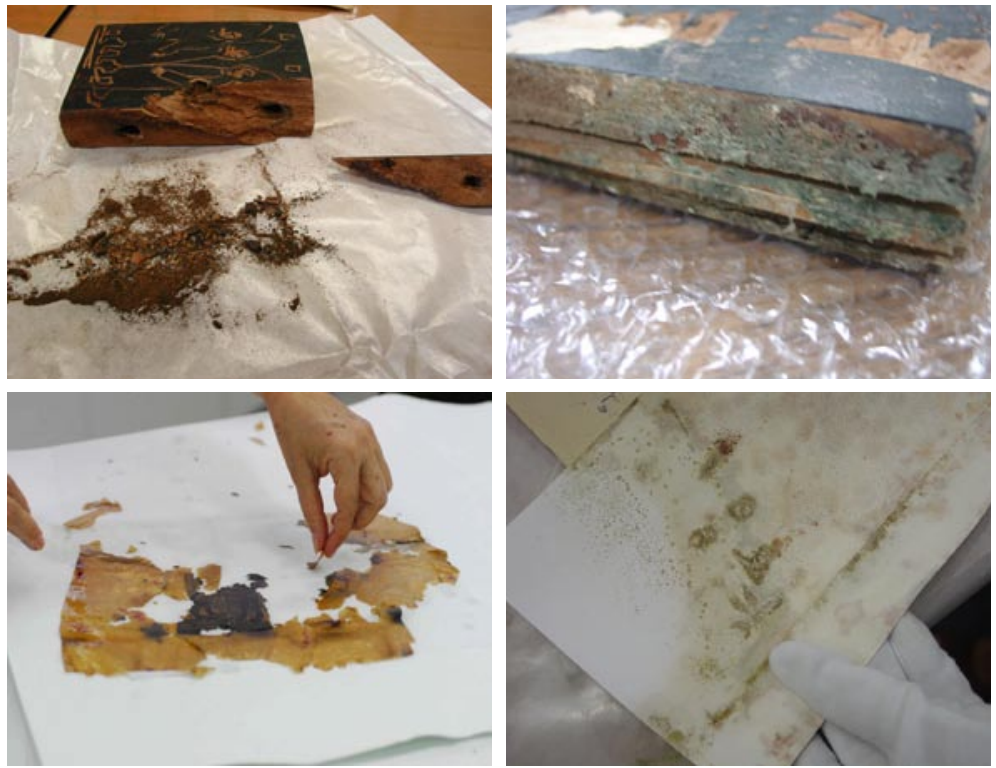

Figura 2: Preparação das matrizes e impressos de xilogravura no IEB para irradiação.
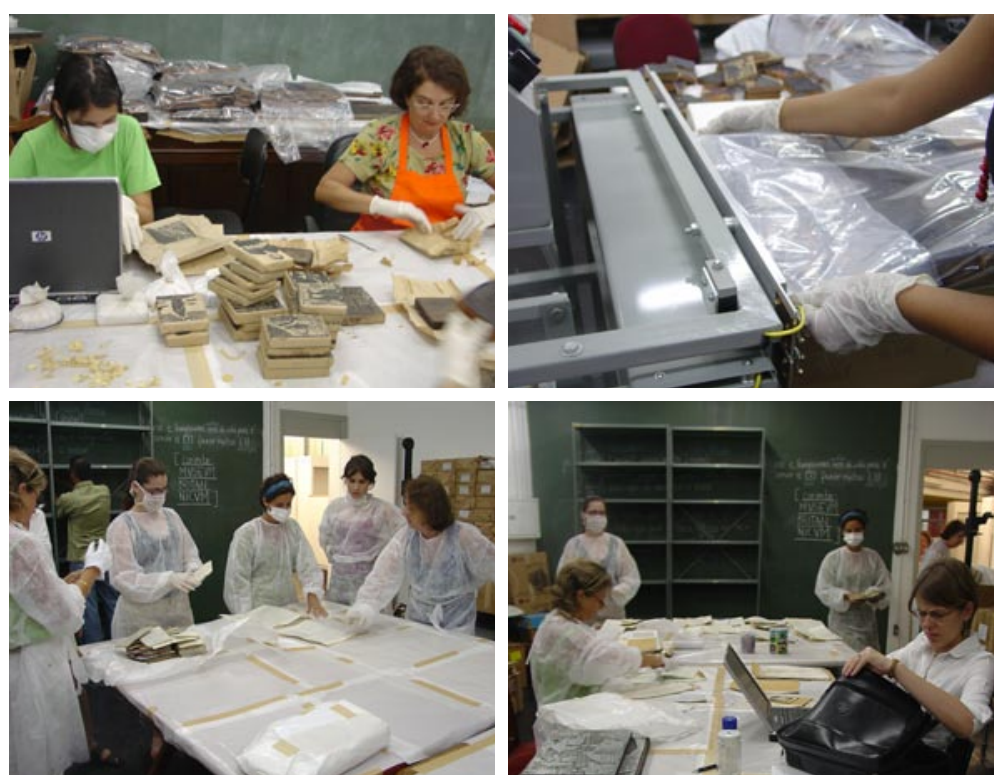
Figura 3: Irradiador multipropósito do IPEN/CTR.

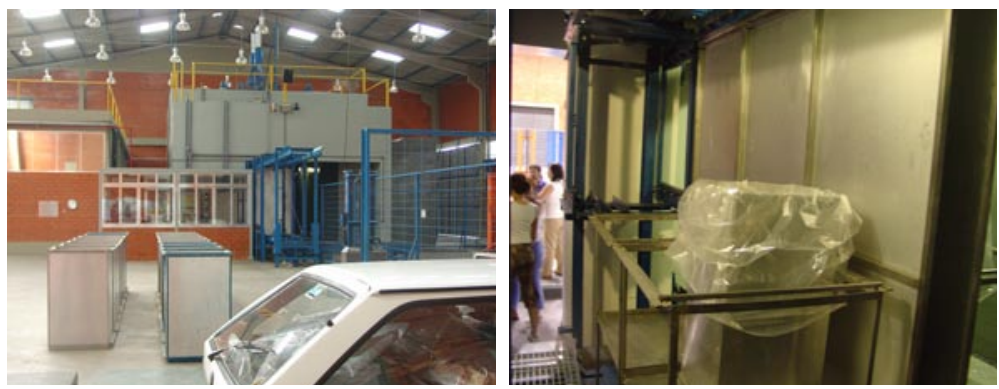

Figura 4: Matrizes de xilogravura durante o processo de restauro.
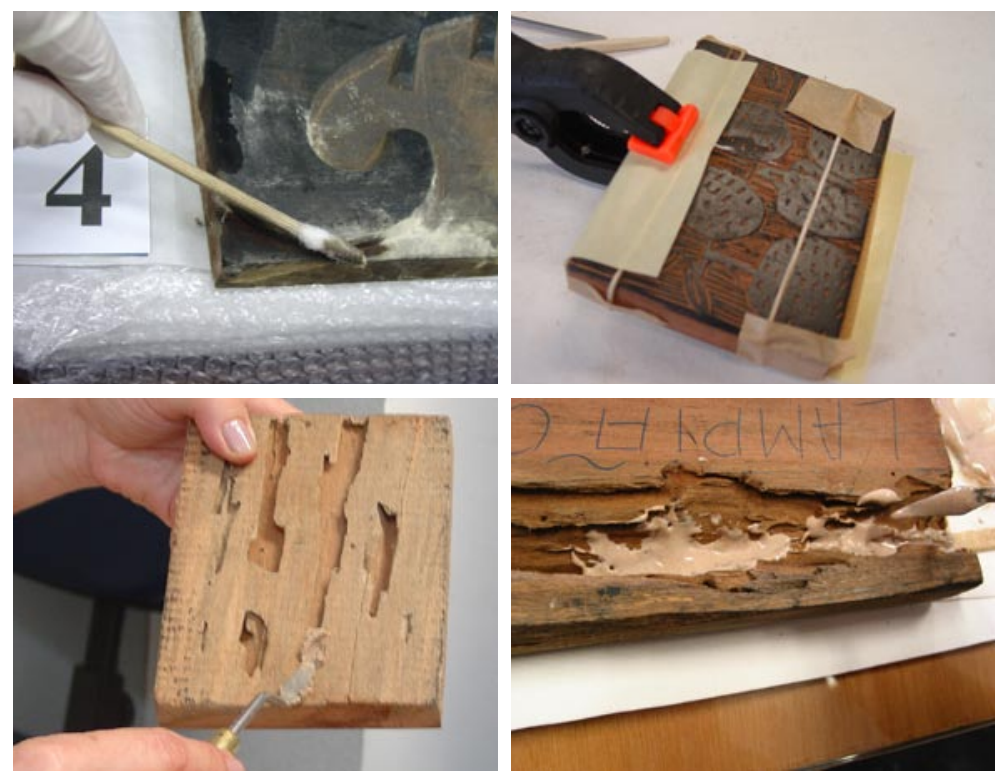
Figura 5: Xilogravura e fibras do papel esgarçadas mostrando infestação por fungos.
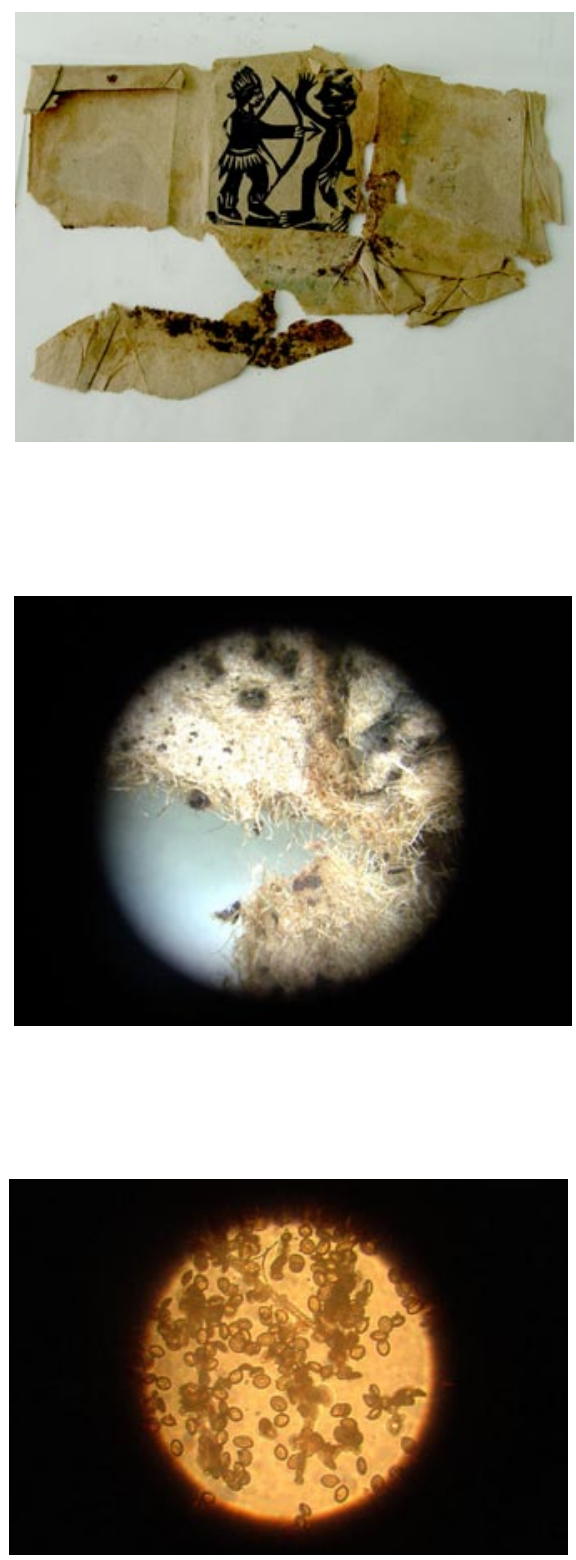
Figura 6: Impressões de xilogravura durante o processo de restauro.
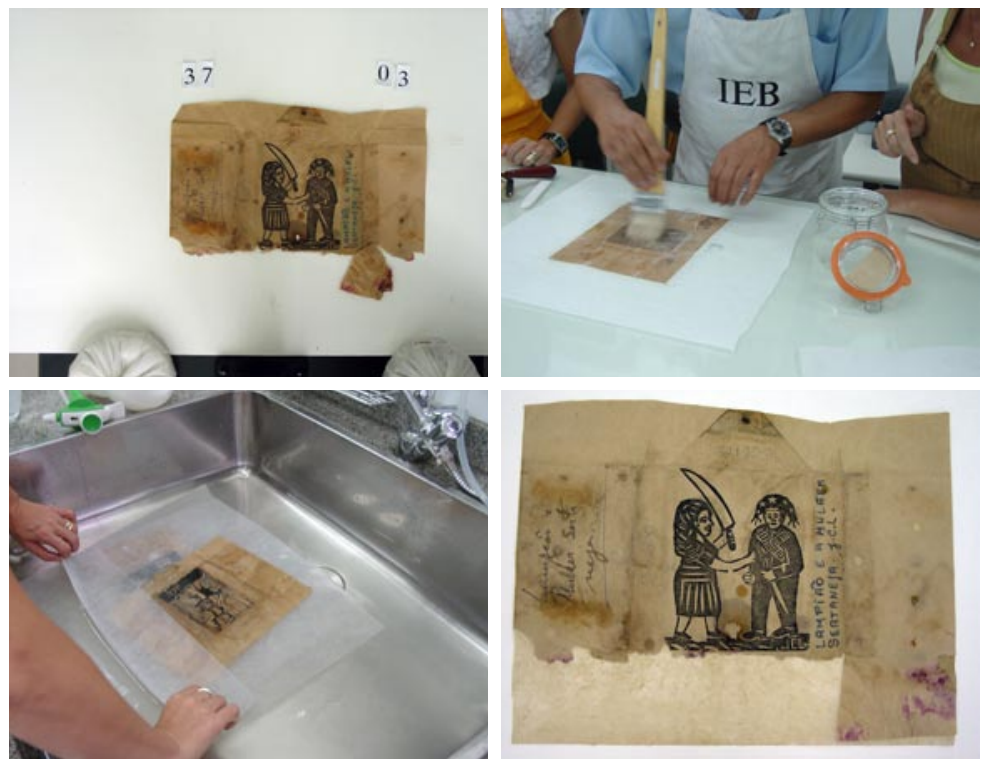